\title{
Overexpressed HDAC8 in cervical cancer cells shows functional redundancy of tubulin deacetylation with HDAC6
}

\author{
G. R. Vanaja ${ }^{1}$, Hemalatha Golaconda Ramulu² and Arunasree M. Kalle ${ }^{1^{*}}$
}

\begin{abstract}
Background: Histone deacetylases (HDACs) are involved in epigenetic gene regulation via deacetylation of acetylated lysine residues of both histone and non-histone proteins. Among the 18 HDACs identified in humans, HDAC8, a class I HDAC, is best understood structurally and enzymatically. However, its precise subcellular location, function in normal cellular physiology, its protein partners and substrates still remain elusive.

Methods: The subcellular localization of HDAC8 was studied using immunofluorescence and confocal imaging. The binding parterns were identified employing immunoprecipitation (IP) followed by MALDI-TOF analysis and confirmed using in-silico protein-protein interaction studies, HPLC-based in vitro deacetylation assay, intrinsic fluorescence spectrophotometric analysis, Circular dichroism (CD) and Surface Plasmon Resonance (SPR). Functional characterization of the binding was carried out using immunoblot and knockdown by siRNA. Using one way ANOVA statistical significance $(n=3)$ was determined.
\end{abstract}

Results: Here, we show that HDAC8 and its phosphorylated form (pHDAC8) localized predominantly in the cytoplasm in cancerous, HeLa, and non-cancerous (normal), HEK293T, cells, although nucleolar localization was observed in HeLa cells. The study identified Alpha tubulin as a novel interacting partner of HDAC8. Further, the results indicated binding and deacetylation of tubulin at ac-lys40 by HDAC8. Knockdown of HDAC8 by siRNA, inhibition of HDAC8 and/or HDAC6 by PCl-34051 and tubastatin respectively, cell-migration, cell morphology and cell cycle analysis clearly explained HDAC8 as tubulin deacetylase in HeLa cells and HDAC6 in HEK 293 T cells.

Conclusions: HDAC8 shows functional redundancy with HDAC6 when overexpressed in cervical cancer cells, HeLa, and deacetylaes ac-lys 40 of alpha tubulin leading to cervical cancer proliferation and progression.

Keywords: HDAC8, Alpha tubulin, Tubulin deacetylase, HDAC6, Cervical cancer

\section{Background}

Histone deacetylases (HDACs) are class of enzymes known to deacetylate the $\varepsilon$-amino groups of acetylated lysine residues of both histone and non-histone proteins [1] and are divided into four different classes: Class I: HDACs 1, 2, 3, and 8, Class II: HDACs 4,5, 6, 7, 9, 10, Class III: Sirtuins, SIRT1-SIRT7, and Class IV: HDAC11 [2]. Zinc dependent hydrolases class of HDACs (I, II and IV) are commonly referred to as "Classical" HDACs [3]. Given the role of HDACs in epigenetic gene regulation and protein activity

\footnotetext{
*Correspondence: arunasreemk@uohyd.ac.in

${ }^{1}$ Department of Animal Biology, School of Life Sciences, University of Hyderabad, Hyderabad, TS 500046, India

Full list of author information is available at the end of the article
}

regulation, identification and characterization of endogenous substrates of HDAC enzymes is a promising area of HDAC research [1].

HDAC8, the best structurally characterized [4] of all HDACs is known to be the first human HDAC to be crystallized with bound inhibitors [5-8]. Histone proteins such as $\mathrm{H} 2 \mathrm{~A} / \mathrm{H} 2 \mathrm{~B}, \mathrm{H} 3$, and $\mathrm{H} 4$ and non-histone proteins such as p53, $\alpha$-actin, CREB etc. have been identified as substrates of HDAC8 [9]. Overexpression of HDAC8 is clinically observed in some of the adult tissue cancers like colon, breast, lung, pancreas, liver and childhood neuroblastoma [10, 11]. Knockdown of HDAC8 using siRNA has shown to inhibit human lung, colon, and cervical cancer proliferation [6]. Interestingly, HDAC8 knockdown

(c) The Author(s). 2018 Open Access This article is distributed under the terms of the Creative Commons Attribution 4.0 International License (http://creativecommons.org/licenses/by/4.0/), which permits unrestricted use, distribution, and 
did not affect the overall histone acetylation [11]. In view of the role of identified HDAC8 substrates in cellular homeostasis and the role of HDAC8 in tumorigenesis, it is important to identify and characterize the functional significance of other novel protein substrates of HDAC8.

In the present study an attempt is made to identify and characterize novel HDAC8 substrates.

\section{Methods \\ Materials}

Forskolin was purchased from Sigma (USA). PCI-34051 and Tubastatin were procured from Cayman chemicals. DMEM, FBS, 1\% Penicillin \& Streptomycin Antibiotics were obtained from Himedia. Monoclonal antibody of HDAC8 (A-4008) was obtained from Epigenetik, Beta actin ab8227 (Abcam), GAPDH (MA5-15738), Alpha tubulin (B-5-1-2) and anti-acetylated alpha tubulin (Cat no: 322700) were purchased from Thermo scientific Life technologies respectively. Protein A Agarose beads were obtained from Santa Cruz. Poly-L-Lysine (Sigma P8920), 4', 6-Diamindino-2-phenylindole dichloride DAPI as a nuclear stain (Sigma), Alexa Fluor 555 Dye (Thermo Fischer Scientific). HDAC8 FLUOR DE LYS fluorometric assay kit (BML-AK518-0001) was purchased from Enzo life sciences. Propidium iodide was purchased from Himedia. GST Column (GE Healthcare 17-5132-01), Custom synthesized peptides of alpha tubulin 33-46 amino acids, Acetylated alpha tubulin peptide, at Lys 40 DGQMPSDKTIGGGD and Unacetylated Alpha tubulin peptide DGQMPSDKTIGGGD from SIGMA (USA) (resuspended in MilliQ water).

\section{Cell culture and treatments}

Human embryonic kidney cells, HEK293T, human cervical carcinoma cells, HeLa, human breast cancer cells, MDAMB 231, human lung adenocarcinoma cellsA549, chronic myeloid leukemia cells, K562, and human colon cancer cells, HCT11, were obtained from National Centre for Cell Sciences (NCCS), Pune, India. Cell line authentication by STR analysis was performed for 10 genetic loci for all the cell lines by Life code, Genomic technologies Pvt. Ltd., and tested for mycoplasma negative by performing PCR (mycoplasma specific genes) using EZdetect PCR kit for mycoplasma detection (CCK009). All the cells were cultured in high glucose DMEM medium containing 10\% foetal bovine serum and $1 \%$ Penicillin/streptomycin (Himedia). Cells were seeded in $60 \mathrm{~mm}$ dishes and upon attaining 80-90\% confluency, treatment was given with PCI-34051(Cayman Chemicals) $(10 \mu \mathrm{M} / 20 \mu \mathrm{M})$ [12] and tubastatin $(5 \mu \mathrm{M})$ for $24 \mathrm{~h}$ [12] or both in combination (PCI-34051 and Tubastatin) and Forskolin (Sigma) $(10 \mu \mathrm{M})$ for 45 min independently along with untreated control as described earlier [13].

\section{Immunofluorescence}

HeLa and HEK 293 T cells (Control, Forskolin, PCI-34051 $(20 \mu \mathrm{M})$ treated) were fixed with $4 \%$ formaldehyde in PBS for $20 \mathrm{~min}$ at RT followed by permeabilization with $0.25 \%$ TritonX-100 in PBS. Nucleolus from HeLa cells isolated according to the standard protocol [14] were also fixed and permeabilized as above and immunofluorescence was performed as described previously [15].

\section{HDAC8 enzyme activity assay}

HDAC8 enzyme activity assay was performed using HDAC8 FLUOR DE LYS fluorometric assay kit (Cat\# BML-AK5180001) for Control, PCI-34051 $(10 \mu \mathrm{M})$, Forskolin $(10 \mu \mathrm{M})$, Tubastatin $(5 \mu \mathrm{M})$ - treated and immunoprecipitated samples of either total, cytoplasmic and nuclear fractions of HeLa and HEK 293 T cells using anti-HDAC8 antibody and anti-HDAC6 ( $2 \mu \mathrm{g}$ antibody for $\sim 500 \mu \mathrm{g}$ ) according to the manufacturer's protocol.

\section{Immunoprecipitation and MALDI TOF-TOF analysis}

HeLa cells were trypsinized at $90 \%$ confluency, washed with 1XPBS and then lysed in IP Lysis Buffer $(50 \mathrm{mM}$ Tris pH 8.0, $150 \mathrm{mM} \mathrm{NaCl}, 10 \%$ Glycerol, 0.5\% TritonX100, 1X Protease Inhibitor Cocktail). Approx. $500 \mu \mathrm{g}$ of total protein (in duplicates) was incubated with $2 \mu \mathrm{g}$ of Anti-HDAC8 antibody and mouse IgG as an isotypic control at $4{ }^{\circ} \mathrm{C}$ for overnight. Protein A beads $(20 \mu \mathrm{l})$ washed in lysis buffer (thrice) were added to the antibody-lysate mixture and further incubated for $2 \mathrm{~h}$. After $2 \mathrm{~h}$, beads were washed with MSWB Buffer (50 mM Tris pH 8.0, $150 \mathrm{mM} \mathrm{NaCl}, 1 \mathrm{mM}$ EDTA and $0.1 \% \mathrm{NP}-40$ ) for three times at $4{ }^{\circ} \mathrm{C}$. Equal (bead) volume of $2 \mathrm{X}$ sample buffer was then added and separated on 10\% SDS PAGE along with the IgG input. The proteins on gel were visualized by Coomassie staining and differentially obtained bands in the IP sample was gel eluted and subjected to MALDI TOF-TOF analysis.

\section{Western blotting}

Total, cytoplasmic and nuclear fractions of HeLa or HEK $293 \mathrm{~T}$ cells treated with or without PCI-34051 $(20 \mu \mathrm{M})$, [12] tubastatin $(5 \mu \mathrm{M})$ and/or forskolin $(10 \mu \mathrm{M})$ were prepared as described previously [16]. Total protein samples of HEK 293 T, HeLa, MDAMB 231, K562, A549 and HCT11 cells / immunoprecipitated HDAC8 and HDAC6 samples from both HeLa and HEK 293 T lysates / HDAC8 siRNA transfected HEK 293 T and HeLa lysates were also prepared. The proteins were separated on 10 or $12 \%$ SDS-PAGE, transferred on to nitrocellulose membrane and probed with primary antibodies of HDAC8, Beta actin, Alpha tubulin, anti-acetylated alpha tubulin, HDAC6 and GAPDH. The bands were visualized using chemiluminiscence after probing with HRP-conjugated secondary antibody. 


\section{Sequence analysis and homology modelling}

The amino acid sequences of tubulins were retrieved from NCBI database (Accession numbers: AAH33064.1, AAH20946.1, and AAF34188.1 for alpha, beta and gamma tubulin respectively). They were further subjected to multiple sequence alignment using Clustal omega [17] to infer sequence conservation among the tubulin proteins. The sequences were analysed for functional conserved regions using Pfam database [18]. The crystal structures for beta-tubulin (PDB ID: 2XRP_A) and gamma-tubulin (PDB ID: 3CB2_A) were available in the database. However, Alpha-tubulin $\mathrm{c}$ did not have any structure in PDB and therefore its structure was built using homology modelling. Protein BLAST in eukaryotic genomes was carried out to analyse the sequence homology and identity. Homology modelling of Alpha tubulin was carried out by I-TASSER, an online webserver for protein structure prediction and structure-based function annotation [19]. The tertiary structure prediction was performed by ITASSER server by using the best align template. Out of the generated models of the target sequence, the best template (PDB ID: 4I4T_A) was selected based on the significant sequence identity, C-Score, TM score and RMSD values of template structure.

\section{Protein-protein interaction studies}

Protein-protein interaction studies of tubulins (alpha, beta, gamma) were carried out with HDAC8 (PDB ID: 1W22_A) using ZDOCK [20], which is an interactive online based server for docking protein-protein complexes.

\section{Purification of GST - hHDAC8}

hHDAC8 (Full length) cDNA was amplified by using a polymerase chain reaction (PCR) with forward primer: 5' - GGAATTCATGGAGGAGCCGGAGGAACC-3' and a reverse primer: 5'-CCGCTCGAGCTAGACCACA TGCTTCAGATTCCC-3'. The PCR product was then sub cloned into pGEX-6P1 plasmid. Clone was then overexpressed in Escherichia coli strain BL21 (DE3) with standardized expression conditions of $0.1 \mathrm{mM}$ IPTG at $28{ }^{\circ} \mathrm{C}$ for $4 \mathrm{~h}$. Induced culture pellet was lysed in 1XPBS buffer (140 mM NaCl, $2.7 \mathrm{mM} \mathrm{KCl,} 10 \mathrm{mM} \mathrm{Na} 2 \mathrm{HPO}_{4}, 1.8 \mathrm{mM}$ $\mathrm{KH}_{2} \mathrm{PO}_{4}$ ) along with $1 \mathrm{X}$ Protease inhibitor cocktail, $1 \mathrm{mM}$ PMSF, and $0.1 \mathrm{mM}$ DTT. To the lysate $1 \%$ Triton X 100 is added and centrifuged for $20 \mathrm{~min}$ at a speed of $4000 \mathrm{rpm}$ at $4{ }^{\circ} \mathrm{C}$. Clear supernatant was used for binding with GST binding buffer (25 mM Tris pH 7.5, $300 \mathrm{mM}$ $\mathrm{NaCl}, 1 \mathrm{mM}$ EDTA, $1 \mathrm{X}$ Protease inhibitor cocktail) for $3 \mathrm{~h}$ on a rota spin at $4{ }^{\circ} \mathrm{C}$. Binding was followed by collection of unbound and washes with 1X PBS (5 washes). Elutions were collected in $10 \mathrm{mM}$ reduced glutathione, dissolved in $50 \mathrm{mM}$ Tris $\mathrm{pH}$ 8.0. The purity of the protein was then analysed on SDS PAGE, followed by
Western blot. Activity was then determined by HDAC activity assay.

\section{Fluorescence spectrometry studies}

Binding studies of GST-HDAC8 \& alpha tubulin peptides (ac \& Unac) forms were carried out using Perkin Elmer precisely LS55 fluorescence spectrometry. Pure GSTHDAC8 $(1-2 \mu \mathrm{M})$ was incubated with acetylated $(500 \mathrm{nM})$ and unacetylated alpha tubulin peptides (500 nM) independently, with time dependence from 5 to $30 \mathrm{~min}$, at $37^{\circ} \mathrm{C}$ in Tris $50 \mathrm{mM} \mathrm{pH} \mathrm{8.0.} \mathrm{The} \mathrm{decrease} \mathrm{in} \mathrm{the} \mathrm{intrinsic}$ fluorescence of GST-HDAC8 with both the conditions time dependently are read at 300-500 nm. The decrease in the fluorescence intensity was plotted against the wavelength $(\mathrm{nm})$.

\section{Circular dichroism spectroscopy studies}

Binding studies of GST-HDAC8 protein $(2 \mu \mathrm{M})$ and acetylated (Lys40) or unacetylated alpha tubulin peptides (500 nM) were carried out on Jasco J-1500 (model L-1500450) CD spectroscopy. Changes incurred in the secondary structure of GST-HDAC8 upon binding of the peptides were recorded as the mean ellipticity, with given set of parameters: start wavelength of $300 \mathrm{~nm}$, end wavelength of $190 \mathrm{~nm}$, scan speed of $100 \mathrm{~nm} / \mathrm{min}$, band width of $2 \mathrm{~nm}$, cuvette cell size of $2 \mathrm{~mm}$ and at a temperature of $25{ }^{\circ} \mathrm{C}$ with two scan accumulations.

\section{In vitro deacetylation assay}

In vitro deacetylation assay of custom synthesized acetylated (Lys40) alpha tubulin was carried out on HPLC (Schimadzu) with $\mathrm{C} 18(4.6 \times 250 \mathrm{~mm})$ column as described earlier [21]. Briefly, the unacetylated or acetylated tubulin peptides (500 nM) were incubated with purified GST-HDAC8 protein $(2 \mu \mathrm{M})$ for $15 \mathrm{~min}$ at $37^{\circ} \mathrm{C}$ in $50 \mathrm{mM}$ Tris $\mathrm{pH} 7.5$, $1 \mathrm{mM}$ DTT buffer. The reaction was then quenched by addition of $1 \%$ TFA to the final reaction volume of $110 \mu \mathrm{l}$ and injected into HPLC.

\section{RNA interference (siRNA) studies}

Source for siRNA oligonucleotides were considered from [22] with sequence, HDAC8 Sense: GACGGAAAUUUG AGCGUAUUCUCU and Anti-sense: UAGAGAAUACGCUCAAAUUUCCGU. The oligonucleotides were converted into siRNA by following standard protocol as described earlier [23]. HeLa and HEK 293 T cells were transfected with HDAC8 siRNA (10-15 $\mu \mathrm{g} / 100 \mathrm{~mm}$ dish) using lipofectamine 2000 (Invitrogen), and considering untransfected as control. Cells were harvested after $72 \mathrm{~h}$ of post-transfection and processed for total RNA and protein isolation. 


\section{Real time analysis}

HeLa and HEK 293 T cells treated with PCI-34051 (20 $\mu \mathrm{M})$ or Paclitaxel $(20 \mu \mathrm{M})$ for $24 \mathrm{~h}$ or HDAC8 siRNA (10$15 \mu \mathrm{g} / 100 \mathrm{~mm}$ dish) transfected HEK $293 \mathrm{~T}$ and HeLa for $72 \mathrm{~h}$, along with control were subjected to total RNA isolation by using TRIZOL (Sigma-Aldrich, USA). As per the manufacturers protocol $1 \mu \mathrm{g}$ of RNA was reverse transcribed with reverse transcription kit, (Invitrogen). Real-time RT-PCR was performed on Applied Biosystems StepOnePlus ${ }^{\mathrm{Tx}}$ Instrument using KAPA SYBR ${ }^{\circ}$ FAST qPCR master mix and gene-specific primers. The experiment was repeated twice, which were performed in duplicates. Fold expression determination, gene-to-GAPDH ratios were determined by using the $2^{-\Delta \Delta C t}$ method. Details of the primers used are listed in the (Table. 1).

\section{Cell migration assay}

HeLa cells are grown in 6 well plates in duplicates till it attains $90 \%$ confluency and starved with serum free media for overnight. Using a sterile $200 \mu \mathrm{l}$ tip wound is created by drawing straight lines at three different points in each well. Detached cells are aspirated and washed three times with 1XPBS. Cells are treated with PCI-34051 $(10 \mu \mathrm{M}$ \& $20 \mu \mathrm{M})$ and Paclitaxel $(10 \mu \mathrm{M} \& 20 \mu \mathrm{M})$ dissolved in $2 \%$ FBS respectively along with control (untreated). Migrated cells into the wound were examined by capturing images using Olympus CKX41, ProgRes CT3 phase contrast microscope after 24 and $48 \mathrm{~h}$.

\section{Cell morphology analysis}

HeLa and HEK 293 T cells are cultured in 6 well plates till attaining $70 \%$ confluency. Cells are starved for $12 \mathrm{~h}$ without serum and treated with PCI-34051 $(20 \mu \mathrm{M})$ and Paclitaxel $(20 \mu \mathrm{M})$ along with untreated control for 24 \& $48 \mathrm{~h}$. Examined difference in the morphology was captured by Olympus CKX41, ProgRes CT3 phase contrast microscope at 10X focussed lens.

\section{Cell cycle analysis}

Cells (HeLa \& HEK $293 \mathrm{~T}$ ) were grown to attain 70\% confluency and were serum starved for $12 \mathrm{~h}$, followed by treatments with PCI-34051 $(20 \mu \mathrm{M})$ and Paclitaxel $(20 \mu \mathrm{M})$ respectively for $48 \mathrm{~h}$ and processed for cell cycle analysis.

\section{Statistical analysis}

The statistical analysis was performed using one-way analysis of variance (ANNOVA) using GraphPad Prism software and statistical significance established $(p<0.05)$ was indicated by *.

\section{Results \\ HDAC8 is localized predominantly to cytoplasm}

To identify novel HDAC8 substrates, we have employed two different cell lines - cancerous cervical epithelial cells, HeLa cells, where HDAC8 is overexpressed and the other, non-cancerous HEK $293 \mathrm{~T}$ cells, considered as "normal" with basal level of HDAC8 expression.

In the present study, the confocal microscopic analysis confirms the predominant cytoplasmic localization of HDAC8 in both HEK293T and HeLa cells (Fig. 1a) unlike other class I HDACs and our results are in agreement with the earlier studies [4, 24-26]. However, in HeLa cells, nucleolar expression of HDAC8 was also observed which was not seen in HEK293T cells (Fig. 1b). Such nucleolar localization of a protein involved in transcriptional regulation and gene repression in cancer cells was observed with CCCTC-binding factor (CTCF) [27]. Exploring the role of HDAC8 in nucleolus would be interesting and is not in the scope of this study.

HDAC8 is also known to be phosphorylated at Ser39 position by Protein kinase A (PKA) and its activity decreases with phosphorylation [13]. The class II HDACs are known to shuttle between cytoplasm and nucleus when phosphorylated. Therefore, we next analysed the cellular location of p-HDAC8 by treating cells with forskolin, an activator of PKA. The confocal images revealed no difference in localization of HDAC8 suggesting, HDAC8 and its phospho-form are majorly cytoplasmic in location (Fig. 1c).

The cytoplasmic localization of HDAC8 was further confirmed by immunoblot analysis using total, cytoplasmic and nuclear protein fractions of HEK $293 \mathrm{~T}$ and HeLa (Fig. 1d). HDAC8 enzyme activity assay using the immunoprecipitated fractions of total, cytoplasmic and nuclear proteins of untreated and PCI-34051- treated (a HDAC8 selective inhibitor [28]) HeLa [Fig. 1e (a)] and HEK $293 \mathrm{~T}$ [Fig. 1e (b)] cells demonstrated that both cytoplasmic and nuclear HDAC8 were active implicating

Table 1 List of Primers used for Real Time PCR Analysis

\begin{tabular}{lllll}
\hline SNo & Gene & Sequence & Annealing Temp. $\left({ }^{\circ} \mathrm{C}\right)$ & Amplicon size (bp) \\
\hline 1 & GAPDH & FP: 5' - GAGAAGGCTGGGGCTCATTGG - 3' & 61 & 145 \\
& & RP: 5' - TGGTGAGGAGGCATTGCTGATG - 3' & 141 \\
2 & FP: 5' - GGCTAGGTATGATGCCCAGC - 3' & 60 & 125 \\
3 & RP: 5' - CATGATGCCACCCTCCAGACC - 3' & & 60.5 \\
\hline
\end{tabular}




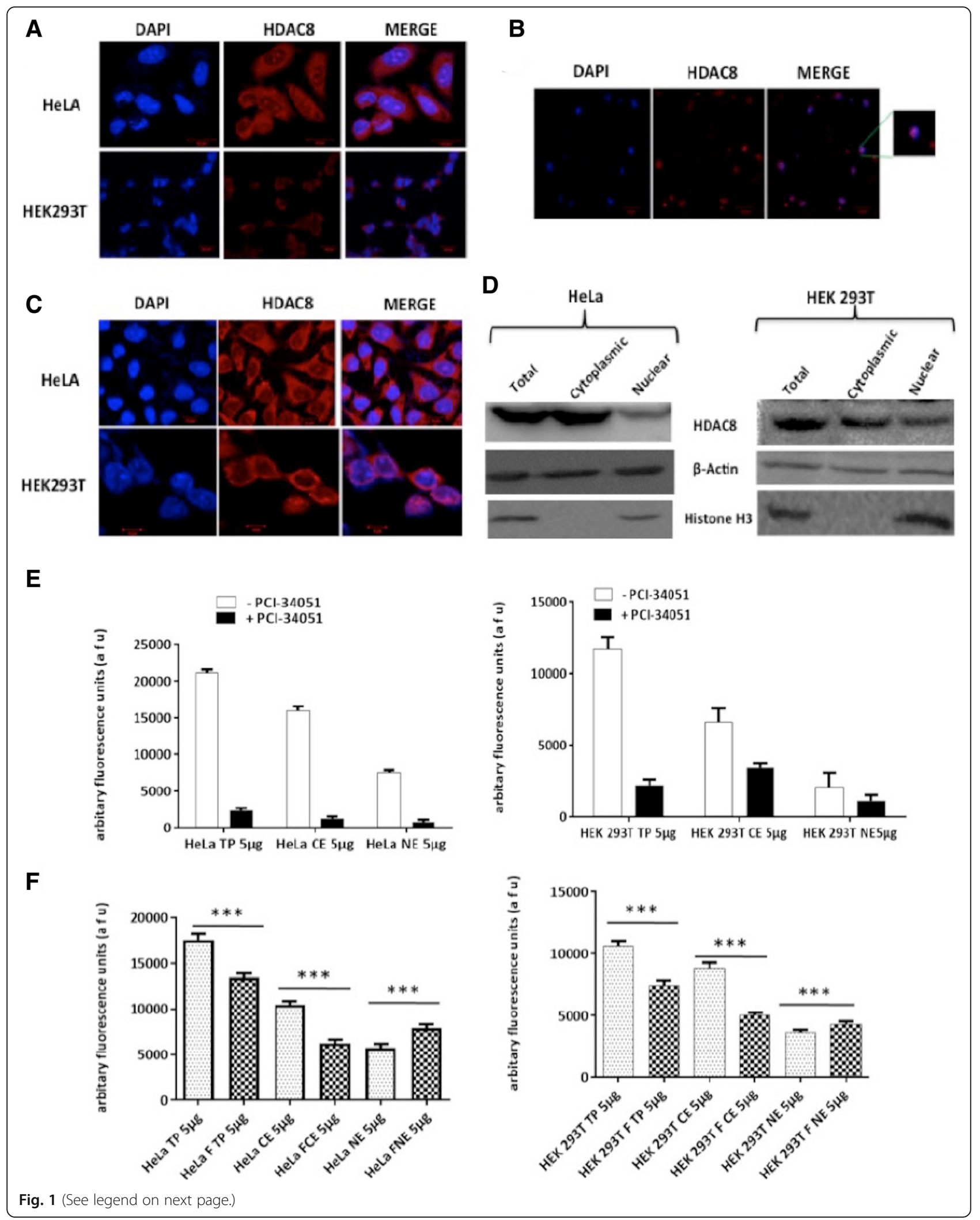


(See figure on previous page.)

Fig. 1 HDAC8 is predominantly cytoplasmic in localization. a Confocal images of HDAC8 localization in HeLa (upper panel) and HEK 293 T (lower panel) (Scale: $20 \mu \mathrm{m}$ ). b Nucleolar localization confirmation of HDAC8 in HeLa (Scale: 20 rm). c Confocal images of HDAC8 localization in Forskolin $(10 \mu \mathrm{M})$ treated HeLa (upper panel) and HEK $293 \mathrm{~T}$ (lower panel) (Scale: $20 \mu \mathrm{m}$ ). d HDAC8 protein levels in total, cytoplasmic and nuclear fractions of


$5 \mu \mathrm{g}$ fractions in presence or absence of specific inhibitor PCI-34051 (10 $\mu \mathrm{M})$ in HeLa and HEK 293 T respectively. $\mathbf{f}$ HDAC8 enzyme activity assay with Forskolin $(10 \mu \mathrm{M})$ treated, HDAC8 Immunoprecipitated fractions of total $(5 \mu \mathrm{g})$, cytoplasmic (5 $\mu \mathrm{g})$ and (nuclear) $5 \mu \mathrm{g}$ fractions, along with untreated control fractions of HeLa and HEK 293 T respectively. ${ }^{*}$ indicates $p$-value $<0.001$

its functional role both as histone and non-histone deacetylase. With forskolin treatment, there was significant increase in the nuclear fraction when compared to activity of untreated nuclear extract in both HeLa and HEK 293 T [Fig. 1f (a\&b)].

\section{Alpha tubulin is a non-histone substrate of HDAC8}

Identification of protein-protein interactions by mass spectroscopy followed by immunoprecipitation and coIP experiments is a well-established and very useful technique [29]. Several interacting proteins have been identified using this approach. We therefore next tried to identify HDAC8 protein interacting partners by immunoprecipitation followed by MALDI-TOF-TOF analysis. Coomassie staining of the denaturing gel of immunoprecipitated protein samples from HeLa cells showed a very prominent band at approx $50 \mathrm{kDa}$ (Fig. 2a). The protein was gel eluted and subjected to MALDI analysis. Mascot database search results identified protein as Alpha tubulin with a protein score greater than 56 and significant score of $p<0.05$ (Fig. 2b). In view of cytoplasmic localization of HDAC8, we hypothesized Alpha-tubulin can indeed be a novel non-histone protein substrate of HDAC8. Co-IP (Fig. 2c) and reverse-immunoprecipitation (Fig. 2d) results confirmed that HDAC8 and Alpha tubulin do interact not only in cancer cells, HeLa but also in normal HEK 293 T cells.

\section{HDAC8 interacts only with alpha tubulin}

To understand the specificity of HDAC8 towards three isoforms of tubulin proteins, multiple sequence alignment of tubulin proteins using Clustal omega analysis was carried out (Fig. 3a). The analysis showed that Lysine residue at 40th position (K40) is only present in Alpha tubulin and that other tubulin forms lack this lysine residue. Further sequence analysis across different species in eukaryotes revealed the conservation of Lys40 in Alpha-tubulin protein indicating its functional significance (Fig. 3b). These results are in well-agreement with recently published study [30].

The functionally conserved K40 acetylation of Alpha tubulin and lysine deacetylase function of HDAC8, interested us to further evaluate the interaction of alpha tubulin and HDAC8. We used in silico approach to first confirm the protein-protein interaction. Since the crystal structure of Alpha tubulin of human was not available, a homology model was generated using I-D TASSER using 4I4T_A as the template structure. 4I4T_A is crystal structure of tubulin-RB3-TTL-Zampanolide complex from Bos Taurus [31]. It is a hexamer, therefore, Chain A was taken for modelling. The overall 3-D (three dimensional) structural arrangement of the crystal structure and model is conserved (Fig. 3c). More than $75 \%$ amino acid residues in model are in the allowed regions of the Ramachandran plot [32]. According to Verify-3D, the overall quality of the model was found to be $96.5 \%$ and ERRAT program shown that $71 \%$ residues had an averaged 3D-1D score $>=0.2$. The RMSD between the template structure and model was $1.29 \AA$ A. C-score and TM-score were found to be 0.55 and 0.95 respectively within the acceptable ranges validating the model generated.

Protein-protein interaction studies of the tubulin proteins were carried out using HDAC8 (PDB ID: 1W22_A). The Alpha-tubulin model showed an interaction of Lys40 with Pro205 of HDAC8, including the IIe225, Val223, Tyr227 with Tyr225, Lys374, Asn372 and Tyr368 of alpha-tubulin and HDAC8 respectively. Out of Val223, Ile225 and Tyr227 residues of Alpha tubulin, it was observed that only Ile225 of Alpha tubulin is interacting with Tyr225 residue of HDAC8 (Catalytic region). As per interacting residues of HDAC8, Pro205 and Tyr225 residues belong to histone deacetylase catalytic domain [Fig. 3D (a)].

With respect to the beta-tubulin (PDB id: 2XRP_A), the residues Pro160, Val258, Trp344, Asn347 of beta-tubulin were found to be interacting with Arg356, Cys275, Leu308, Lys33 of HDAC8 respectively [Fig. 3D(b)]. Gamma-tubulin residues such as Tyr82, Ala370, Glu327, Asn79, Gln227 were found to be interacting with Pro273, Ser150, Tyr100, Cys352, Gln232 of HDAC8 [Fig. 3D(c)]. The ZDOCK score of the tubulins are provided in (Table. 2). All the Figures related to protein-protein interaction studies were generated using Discovery Studio Visualizer version 4.1.

Further in silico mutational studies were carried out to confirm the interaction between Lys 40 of Alpha tubulin and Pro205 of HDAC8. The Lys (40) of alpha tubulin was replaced with Arginine residue and Pro205 of HDAC8 with Alanine and protein-protein interaction with ZDOCK was performed. However, results did not demonstrate any potential interaction with these in silico amino acid replacements in both HDAC8 and Alpha tubulin due to which there was no figure generated in ZDOCK. 


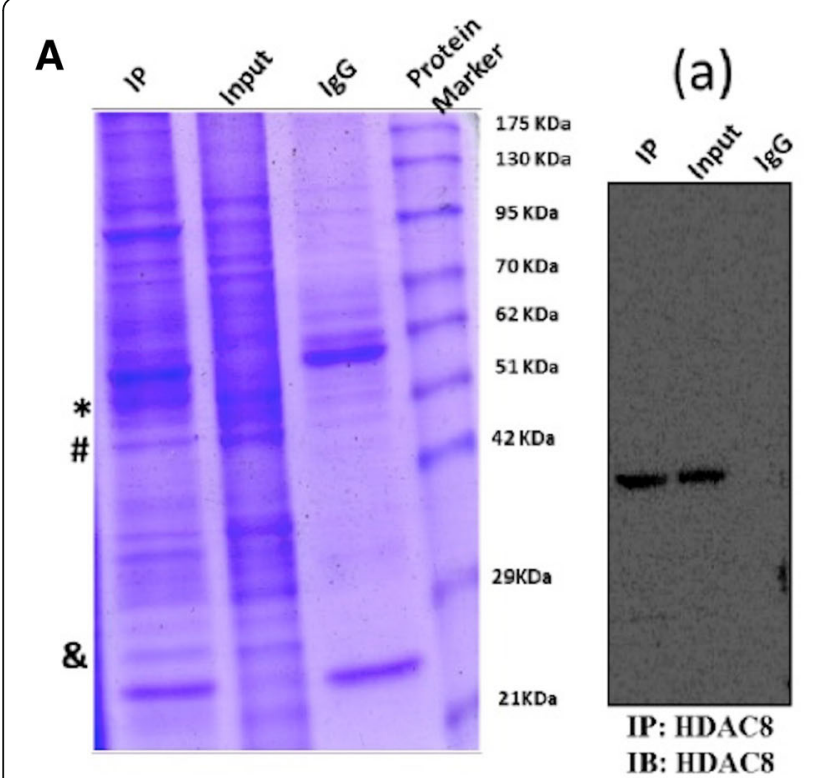

B

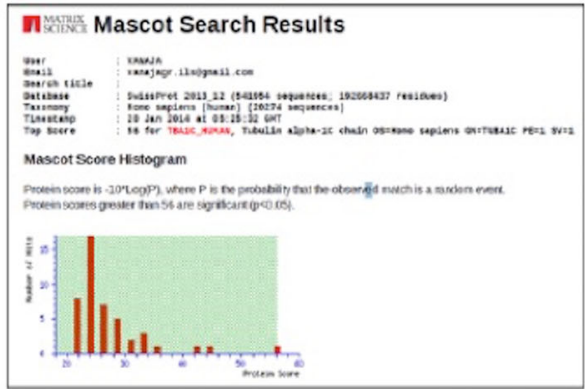

(b)

\begin{tabular}{|c|c|c|c|c|c|}
\hline 5.ro & Name of the protein identified & $\begin{array}{l}\text { Top } \\
\text { Score }\end{array}$ & Origin & $\begin{array}{l}\text { Peptide } \\
\text { matches }\end{array}$ & $\begin{array}{c}\text { Yass } \\
\text { (Daltons) }\end{array}$ \\
\hline 1 & TBAIC-Tubulin Alpha IC & 56 & $\begin{array}{c}\text { Homo } \\
\text { sapiens }\end{array}$ & 12 & 50548 \\
\hline 2 & $\begin{array}{l}\text { RBGIL (Rab GTPase-activating } \\
\text { protein 1- like }\end{array}$ & 36 & $\begin{array}{c}\text { Homo } \\
\text { sapieas }\end{array}$ & 12 & 29038 \\
\hline 3 & NUB1- NEDD8 ult mate buster & 11 & $\begin{array}{c}\text { Homo } \\
\text { sapieas }\end{array}$ & 1 & 71235 \\
\hline 4 & PRP6 Pre-mRVA-processing factor 6 & 7 & $\begin{array}{c}\text { Homo } \\
\text { sapieas }\end{array}$ & 1 & $\mathrm{NA}$ \\
\hline 5 & F228A Protein FAM1228A & 7 & $\begin{array}{c}\text { Homo } \\
\text { sapiens }\end{array}$ & 1 & 23965 \\
\hline 6 & $\begin{array}{l}\text { CHST } 4 \text { Carbohydrate } \\
\text { sulfotransferase } 4\end{array}$ & 6 & $\begin{array}{l}\text { Homo } \\
\text { sapiens }\end{array}$ & 1 & 45560 \\
\hline
\end{tabular}

B
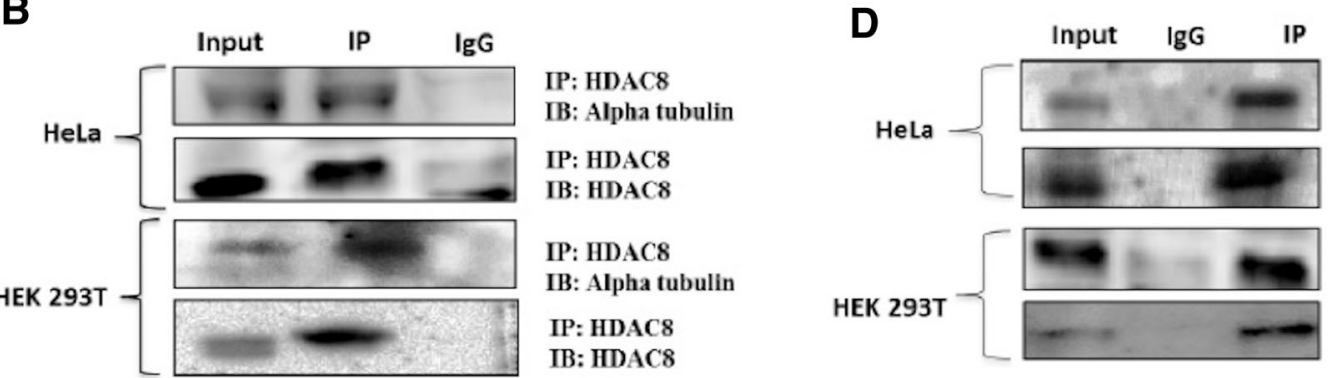

IP: Alpha tubulin
IB: HDAC8
IP: Alpha tubulin
IB: Alpha tubulin
IP: Alpha tubulin
IB: HDAC8
IP: Alpha tubulin
IB: Alpha tubulin

Fig. 2 HDAC8 co-precipitates with Alpha tubulin. a Coommassie stained gel with input and HDAC8-immunoprecipitated HeLa cell lysate along with protein marker. Band at $\left(^{*}\right) \sim 50 \mathrm{kDa}$ and at $\sim 26 \mathrm{kDa}(\&)$ was excised and subjected to MALDI TOF-TOF analysis. (\#) represents for HDAC8 in coomassie gel at $43 \mathrm{kDa}$, further confirmed by immunoblot. b MS analysis and Mascot search results confirmed TUBA1-C (Human Alpha Tubulin chain $1 \mathrm{C}$ isoform) with highest topscore as the interacting partner of HDAC8. c Confirmation of HDAC8 and Alpha tubulin by immunoprecipitation using HDAC8 antibody in HeLa and HEK293T cells. d Reverse IP using Tubulin antibody confirms HDAC8 \& Tubulin interaction in HeLa cells and HEK 293 T respectively

In vitro binding studies were performed for GST-HDAC8 (recombinant purified protein) and alpha tubulin peptides (ac, unac) using fluorescence and circular dichroism spectroscopy technique. Fluorescence spectroscopy analysis demonstrates the change in the intrinsic fluorescence of GST-HDAC8 when incubated with acetylated alpha tubulin time dependently compared to that of unacetylated alpha tubulin (Fig. 3E a\&b). Circular dichroism data suggests that change in the secondary structure of GST-HDAC8 is due to binding of acetylated alpha tubulin, which was not observed with unacetylated tubulin (Fig. 3F).

\section{HDAC8 deacetylates alpha tubulin}

In silico and spectroscopy based results have confirmed the interaction of HDAC8 with alpha tubulin \& acetylated alpha tubulin peptide. To further validate the functional interaction we carried out IP and co-IP experiments with HDAC8 and acetylated alpha tubulin (ac-tubulin) antibodies. The immunoblots clearly showed the HDAC8 and ac-tubulin interaction (Fig. 4a). The levels of ac-tubulin increased significantly when cells were treated with forskolin (Fig. 4b) (known to inactivate HDAC8 by phosphorylation) indicating HDAC8 as a tubulin deacetylase. Densitometry results for the fold expression change of acetylated alpha tubulin normalized with GAPDH (Fig. 4c), clearly demonstrates ac-alpha tubulin as one of the HDAC8 substrate.

To further confirm the deacetylation of ac-tubulin by HDAC8, we carried out HPLC-based deacetylation assay and the HPLC results clearly demonstrated the in vitro deacetylation of acetylated alpha tubulin (Lys40) peptide by GST-HDAC8 with a significant peak shift in the retention time corresponding to unacetylated peptide (Fig. 4d). 
A

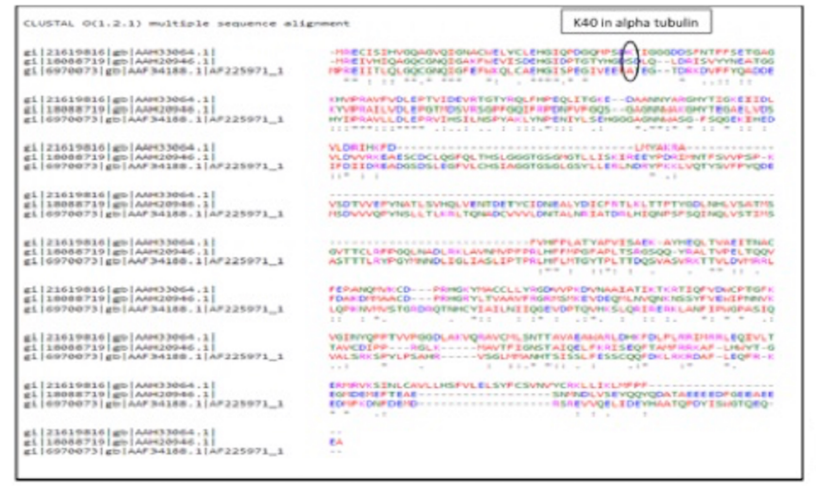

\section{C}

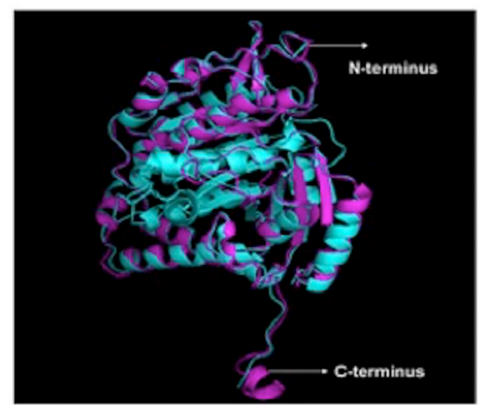

E

(a)

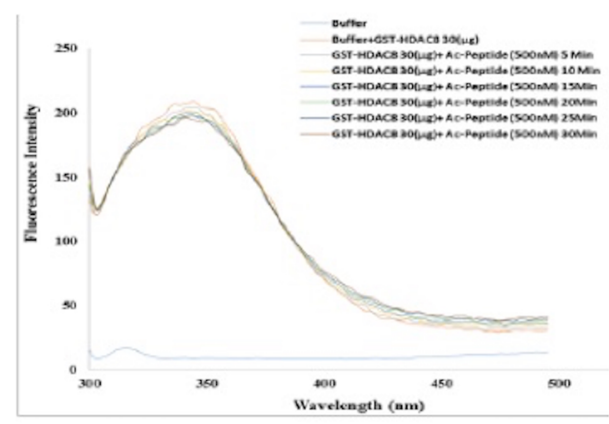

(b)

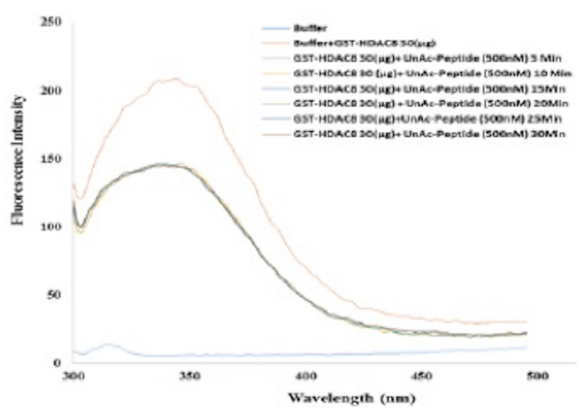

Fig. 3 (See legend on next page.)
B



(a)

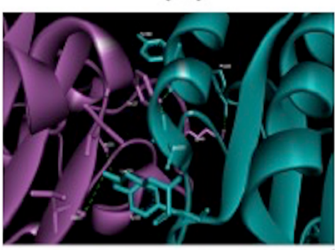

(b)

(c)
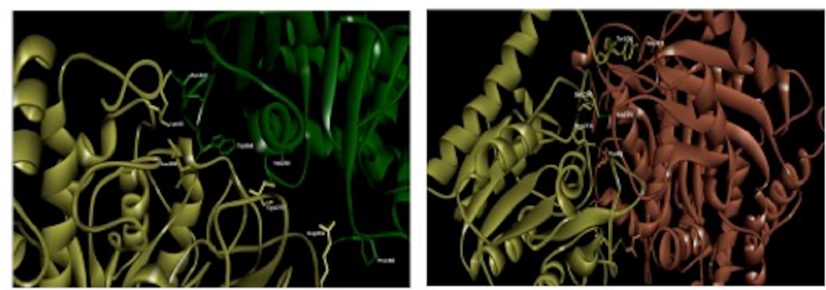

F

(See figure on previous page.)

Fig. 3 In silico analysis of tubulin isoforms and conserved Lys 40 in alpha tubulin. a Clustal omega analysis showing Lys 40 of Alpha tubulin whereas, Beta and Gamma tubulins have serine and alanine respectively. b Lys40 position was found to be conserved in eukaryotes. c 3D crystal structures (generated by homology modelling) of Alpha, Beta and Gamma tubulins, used for studying protein protein interactions with HDAC8. d Protein protein docking studies of HDAC8 with Alpha, Beta and Gamma tubulins. e Fluorescence spectroscopy results of (a) GST-HDAC8 (30 $\mu \mathrm{g}$ ) + ac-alpha tubulin peptide (500 nM) incubation from 5 to 30 min, decreases intrinsic fluorescence. (b) GST-HDAC8 (30 $\mu \mathrm{g})+$ Unac-alpha tubulin peptide $(500 \mathrm{nM})$ incubation from 5 to $30 \mathrm{~min}$, no change in intrinsic fluorescence. $\mathbf{f}$ CD results for change in secondary structure for GST-HDAC8 alone, GST-HDAC8 $(2 \mu \mathrm{M})+$ ac-alpha tubulin peptide $(500 \mathrm{nM})$, and GST-HDAC8 $(2 \mu \mathrm{M})+$ Unac-alpha tubulin peptide (500 nM), significant change in the secondary structure of GST-HDAC8 upon incubating with ac-alpha tubulin clearly signifies the more binding specificity for ac-alpha tubulin but not with unacetylated form

\section{HDAC8 might be primary tubulin deacetylase in HeLa cells}

HDAC6 is a tubulin deacetylase [33]. However, our experimental results also suggested HDAC8 as tubulin deacetylase. In order to understand these results, we have evaluated the expression of HDAC6 and HDAC8 in HEK 293 T, HeLa, MDA-MB-231, A549, K562, and HCT11 cell lines. Results demonstrated that there was no significant difference in HDAC6 expression, when compared between HEK 293 T, HeLa and HCT11. Whereas, A549, K562 and MDA-MB 231 cells have shown two fold higher expression when compared to control HEK 293 T (Fig. 5A and B (a)). On the other hand, HDAC8 is over expressed in HeLa, A549 and HCT11 compared to HEK 293 T (Fig. 5A and B (b)). Based upon the expression pattern of HDAC6 in different cancer cell lines, we presume its role in deacetylating ac-alpha tubulin in HeLa might be taken over by HDAC8 due to its significant overexpression compared to HDAC6.

Next, we have evaluated mRNA and protein levels and HDAC activity of HDAC6 and HDAC8 in HeLa and HEK 293 T cells. The results clearly demonstrated the dominance of HDAC8 in HeLa cells when compared to normal HEK 293 T. On the other hand, there was no significant difference in the HDAC6 expression levels in HeLa and HEK 293 T cells (Fig. 5C, D, E \& F). These results indicate that HDAC6 might be primary tubulin deacetylase; however, the increased HDAC8 in HeLa cells might be taking over the function of HDAC6 as tubulin deacetylase. However, further experiments in various cells showing differential expression of HDAC6 and HDAC8 are warrented.

Table 2 ZDOCK Score for Alpha, Beta and Gamma tubulins

\begin{tabular}{llll}
\hline Protein Name & $\mathrm{S}_{\mathrm{DS}}(\mathrm{k} \mathrm{cal} / \mathrm{mol})$ & $\mathrm{S}_{\text {ELEC }}(\mathrm{k} \mathrm{cal} / \mathrm{mol})$ & $\mathrm{RMSD}(\AA)$ \\
\hline Alpha Tubulin & -2.09 & -2.73 & 1.45 \\
Beta Tubulin & -3.14 & -2.73 & 1.45 \\
Gamma Tubulin & -2.87 & 0.10 & 1.55 \\
\hline
\end{tabular}

$S_{D S}$ indicates sum of Desolvation energy, $S_{E L E C}$ indicates sum of Electrostatic energy, RMSD Root Mean Square Deviation of C-alpha atoms in Angstroms units

As the Desolvation and Electrostatic energy of Alpha tubulin is -2.09 and -2.73 respectively (Range $\leq-3 \mathrm{kcal} / \mathrm{mol}$ ), followed by RMSD values which is $1.45 \AA$ (Range $\leq 2.5 \AA$ ) for Alpha tubulin. This confirms a near native hit when compared to values of beta and gamma tubulin
Next, we tried to determine the effect of HDAC8 and HDAC6 expression on acetylation of tubulin in HEK293T and HeLa cells using specific inhibitors, PCI-34051 and Tubastatin alone or in combination (PCI-34051 + Tubastatin). The increased acetylated alpha tubulin levels in HeLa under PCI-34051 treated conditions when compared to control, clearly demonstrates the possible role of HDAC8 as tubulin deacetylase in HeLa (Fig. 5G and H). The combination treatment (upon inhibition of both HDAC6 \& HDAC8) has shown a clear impact on acetylation of alpha tubulin, which can be explained due to the synergistic effect of dual inhibition of HDAC6 \& 8. In HEK 293 T, there was no significant increase in PCI-34051 treated condition, whereas HDAC6 inhibition resulted in increase in ac-alpha tubulin levels implicating HDAC6 as main tubulin deacetylase in HEK 293 T cells (Fig. 5G and H (b)).

Further we examined the effect of HDAC8 knockdown on acetylation pattern of alpha tubulin using siRNA in both HeLa and HEK 293 T. Real time PCR data confirmed the decreased mRNA expression of HDAC8 in both the cell lines upon siRNA transfection (Fig. 5I). Immunoblot results clearly demonstrated the impact on acetylation pattern of alpha tubulin in both the cell lines [Fig. 5J $(a \& b)]$. This significant increment in the acetylation of alpha tubulin in HDAC8 KD (siRNA knockdown) samples when compared to control, justifies the role of HDAC8 as one of the tubulin deacetylase in HeLa cells. Finally, IP and reverse-IP results of HDAC8 and HDAC6 in HeLa and HEK 293 T further demonstrate their independent mode of activity (Fig. 5K).

\section{HDAC8 alters alpha tubulin functionality}

The results from cell migration assay clearly demonstrated that migration efficiency was significantly decreased in HeLa cells when HDAC8 is inhibited with PCI-34051 upto $48 \mathrm{~h}$ with a notable decrease in cell size (Fig. $6 \mathrm{a} \& \mathrm{~b}$ ).

To further validate the difference in the cell morphology, HeLa and HEK 293 T cells were treated with PCI34051 and Paclitaxel, tubulin polymerization inhibitor, a positive control, for 24 and $48 \mathrm{~h}$. A clear distinguished difference in the cell morphology, with decreased cell size (shrinking) in HeLa, and cell aggregation in HEK $293 \mathrm{~T}$ was observed in both treated conditions when compared with control (Fig. 6c \& d). 


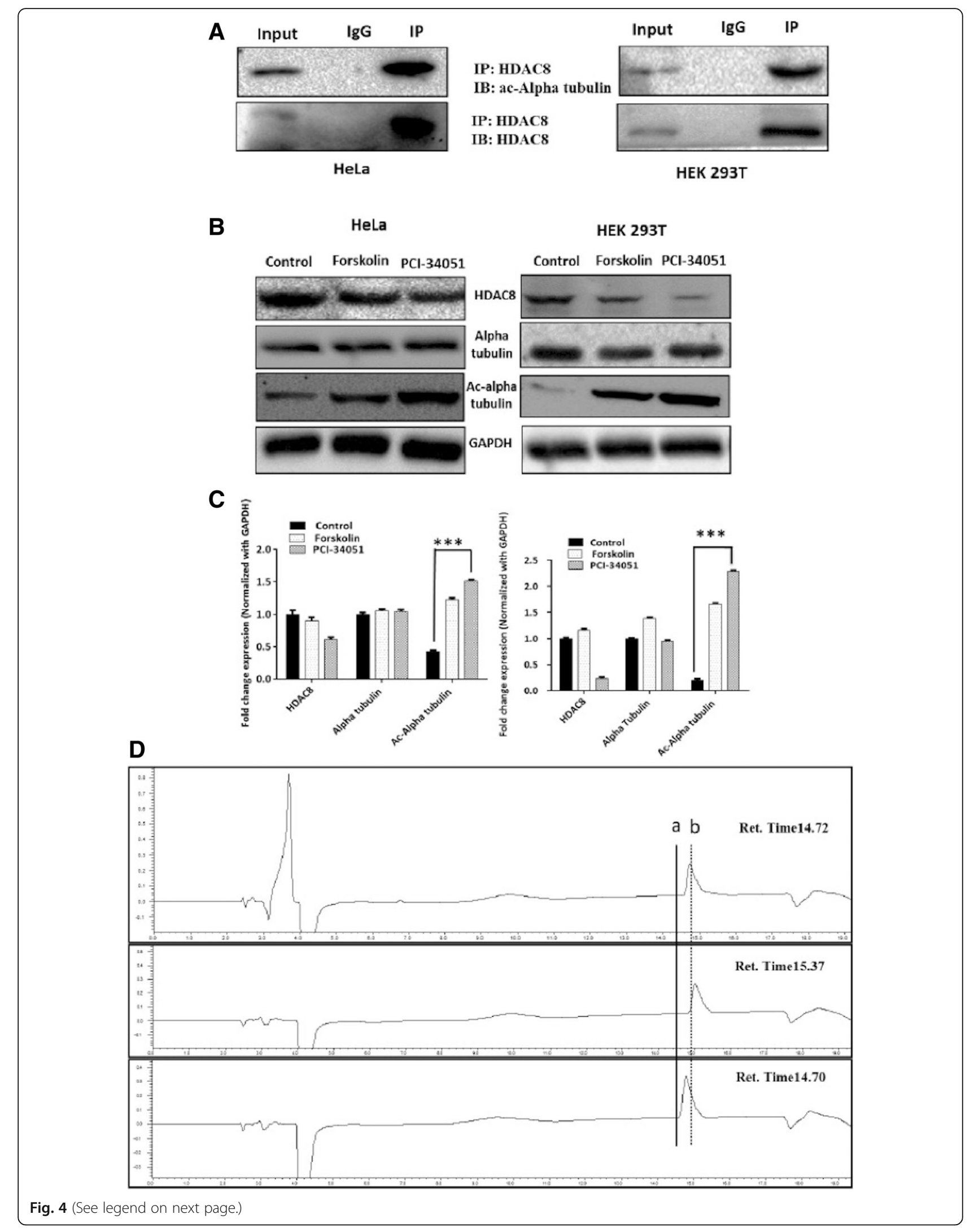


(See figure on previous page.)

Fig. 4 a HDAC8 interacts and deacetylates alpha tubulin. a HDAC8 and Acetylated Alpha tubulin Interaction in HeLa and HEK 293 T cells as demonstrated by immunoprecipitation using HDAC8 antibody followed by immunoblot analysis using ac-alpha tubulin. b ac-alpha tubulin levels


c Densitometry analysis of the immunoblot bands showing fold change in expression pattern of HDAC8, Alpha tubulin and acetylated tubulin normalized with GAPDH. d Lower panel of chromatogram represents for Unac-alpha tubulin peptide with a retention time of 14.70 Min. Middle panel of chromatogram for ac-alpha tubulin with retention time of 15.37 Min. Upper panel of chromatogram for GST-HDAC8 (30 $\mu \mathrm{g})+$ ac-alpha tubulin $(500 \mathrm{nM})$ with a retention time of $14.72 \mathrm{Min}$. Shift in the retention time from a (15.37) to b (14.72) clearly demonstrates the in vitro deacetylation of ac-alpha tubulin by GST-HDAC8

Cell cycle analysis of HeLa cells treated with PCI34051 for 48 h showed an increased sub G0/G1 peak along with a significant $(p<0.05)$ reduction in mitotic phase of cell cycle when compared to untreated control (Fig. 6e). On the other hand, HEK 293 T normal cells did not show any mitotic phase reduction when HDAC8 was inhibited indicating that HDAC6 might be the primary tubulin deacetylase. However, a significant increase in the sub G0/ G1 phase was observed in HEK293T cells treated with PCI-34051 which can be attributed to the inhibition of other normal physiological functions of HDAC8 (Fig. 6f).

\section{Discussion}

HDAC8 belongs to class I HDACs that are generally localized to nucleus and regulate gene expression. Although HDAC8 is well-characterized structurally, its precise cellular loaclization, functional role and the substrates are not known completely [1]. Since HDAC8 is known to be involved in female-specific cancers such as ovary, cervical and breast [10], we have used HeLa cervical cancer cells along with HEK 293 T normal cells so as to get an insight on its role in normal and cancer cells. HDAC8 is known to deacetylate acetylated peptide in vitro implicating its unique behaviour when compared to other class I HDACs that function in protein complexes. In order to better understand this unique nature and identify the protein interacting partners of HDAC8, it is therefore important to first determine the precise cellular localization of HDAC8. Results from our studies clearly demonstrate major cytoplasmic localization of HDAC8, attributing its functional role in deacetylating both histone and nonhistone proteins. Further, the cytoplasmic HDAC8 activity decreased when treated with forskolin, but nuclear HDAC8 enzyme activity increased with forskolin indicating that phospho-HDAC8 might have a role in nucleus such as protecting human ortholog of the yeast evershorter telomeres 1B (hEST1B) from ubiquitination [34]. Evidence from our immunoprecipitation and MALDI TOF TOF, followed by immunoblotting studies further confirms Alpha tubulin as a non-histone interacting partner of HDAC8 irrespective of cancerous (HeLa) and normal cells (HEK $293 \mathrm{~T}$ ).

In silico characterization studies further demonstrated, the uniqueness of conserved $\mathrm{K} 40$ position in alpha tubulin which is known to be acetylated in normal cellular process and is involved in regulation of protein trafficking, cell cycle, and cell migration [30]. Protein-protein interaction studies, with all the three forms of tubulins further validated the importance of alpha tubulin with higher number of interactions, especially Lys40 (a potential acetylation site) of alpha tubulin (catalytic region) with that of Pro205 of HDAC8 (catalytic region). Importance of Lys40 position for its potential interaction with HDAC8 was further validated by in silico mutational analysis (Lys40 to Arg in alpha tubulin \& Pro205 to Ala in HDAC8) which revealed loss of interaction between two proteins. Fluorescence spectrometry is widely used in studying the molecular (binding information) and structural changes in the protein, which is affected by either protein-protein interaction or protein with small molecule interactions. The significant change which occurs around the microenvironment of the aromatic amino acids like Trp, Tyr and Phe are known to induce changes in the intrinsic fluorescence emission properties of the protein, which are measured and analysed [35]. HDAC8 has Trp-4, Phe-13, and Tyr-21 residues respectively. Significant decrease in the fluorescence quenching from $5 \mathrm{~min}$ to $30 \mathrm{~min}$, refers the prominent protein peptide binding interactions. Unacetylated peptide did not show any notable changes in the fluorescence intensities. Circular dichroism studies revealed a significant change in the secondary structure, when incubated with acetylated alpha tubulin, without any notable differences with that of unacetylated form.

IP and Co-IP results for acetylated alpha tubulin with HDAC8, along with functional regulation studies of acetylation levels of alpha tubulin, under forskolin treated condition (phospho-form of HDAC8, known to be less active compared to control) reveals significant increase of acetylated tubulin expression, validating it as a novel substrate for HDAC8, in addition to HDAC6, which is an established tubulin and known to be a target in many of the cancers $[36,37]$. Considering the positive results from our binding studies of GST-HDC8 - ac, unac peptides, in vitro deacetylation assay carried out with GST-HDAC8 incubation with acetylated alpha tubulin peptide (Lys40), clearly admits for its substrate.

As our results clearly demonstrate the role of HDAC8 in deacetylating acetylated alpha tubulin, question arises 




B

C

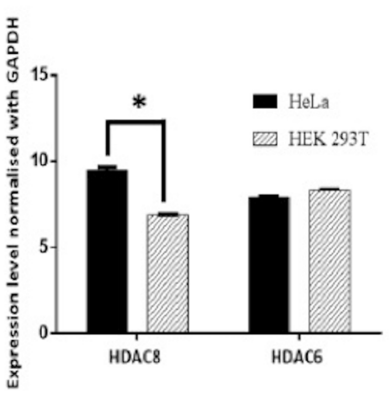

D


(a)
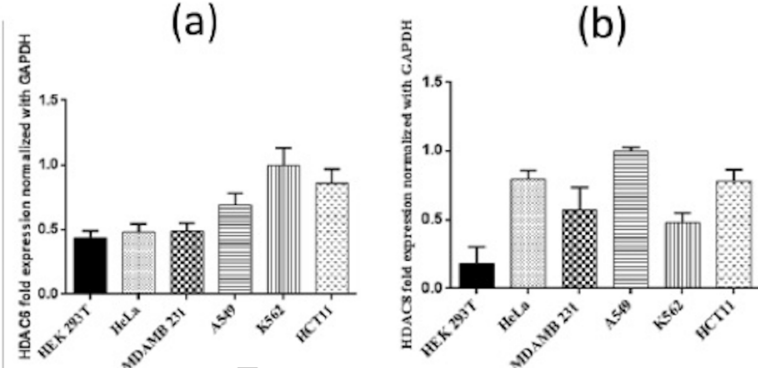

F
G

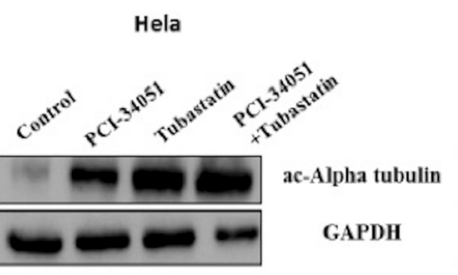

H

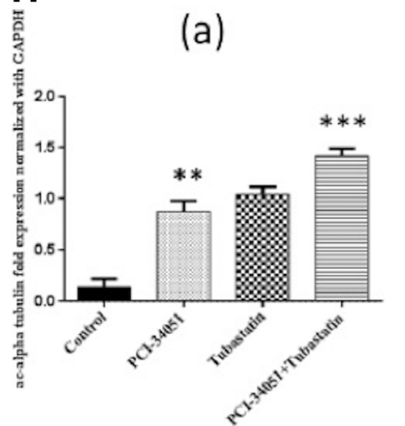

HEK 293 T

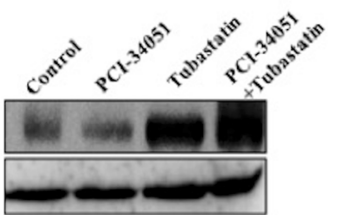

(b)

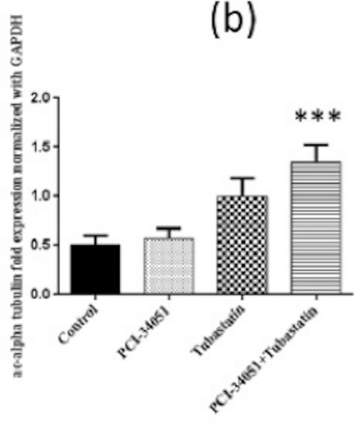

I

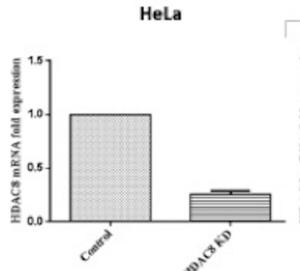

(a)



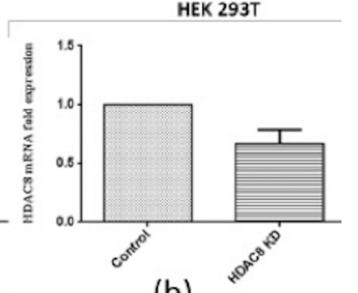

(b)
J

HeLa

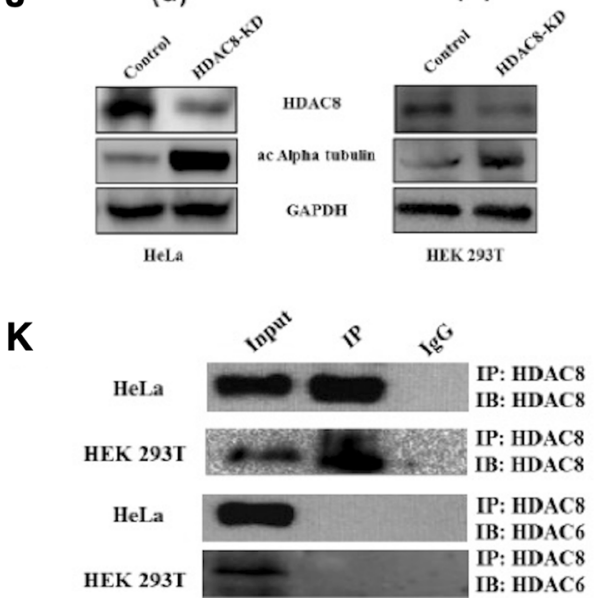

HEK 293T

Fig. 5 HDAC8 might be primary tubulin deacetylase in HeLa cells. a Immunoblot showing the protein expression levels of HDAC8 and HDAC6 in various cancer cell lines. b Densitometric analysis of the (a) HDAC6 bands and (b) HDAC8 bands of immuoblot A. c Real time analysis confirms higher HDAC8 expression compared to HDAC6 in HeLa and HEK 293T normalized with GAPDH * indicates p-value <0.0001. d Protein expression pattern of HDAC8 \& HDAC6 in HeLa and HEK 293T. e Densitometric analysis of bands in Immunoblot D. $\mathbf{f}$ HDAC enzyme activity assay performed with IP Anti-HDAC8 \& IP Anti-HDAC6 with HeLa \&HEK 293T lysates respectively. ${ }^{*}$ indicates $p$-value $<0.0001$. g Increased ac-alpha tubulin levels in presence of PCl-34051 (20 $\mu \mathrm{M})$ when compared to tubastatin $\mu \mathrm{M}$ treated condition in HeLa, whereas, tubastatin $(5 \mu \mathrm{M})$ treatment in HEK $293 \mathrm{~T}$ increases ac-alpha tubulin levels compared to PCl-34051 (20 $\mu \mathrm{M})$ treated condition. $\mathbf{h}$ Densitometry graphs of the immunobands in G. i Real time PCR analysis of the mRNA expression of HDAC8 in HEK 293T and HeLa upon siRNA transfection. $\mathbf{j}$ Immunoblot analysis of HDAC8 and ac-Alpha tubulin in HDAC8 knockdown HeLa (a) and HEK 293T (b) cells. k IP-Co-IP studies of HDAC8 \& HDAC6 in HeLa and HEK 293T 


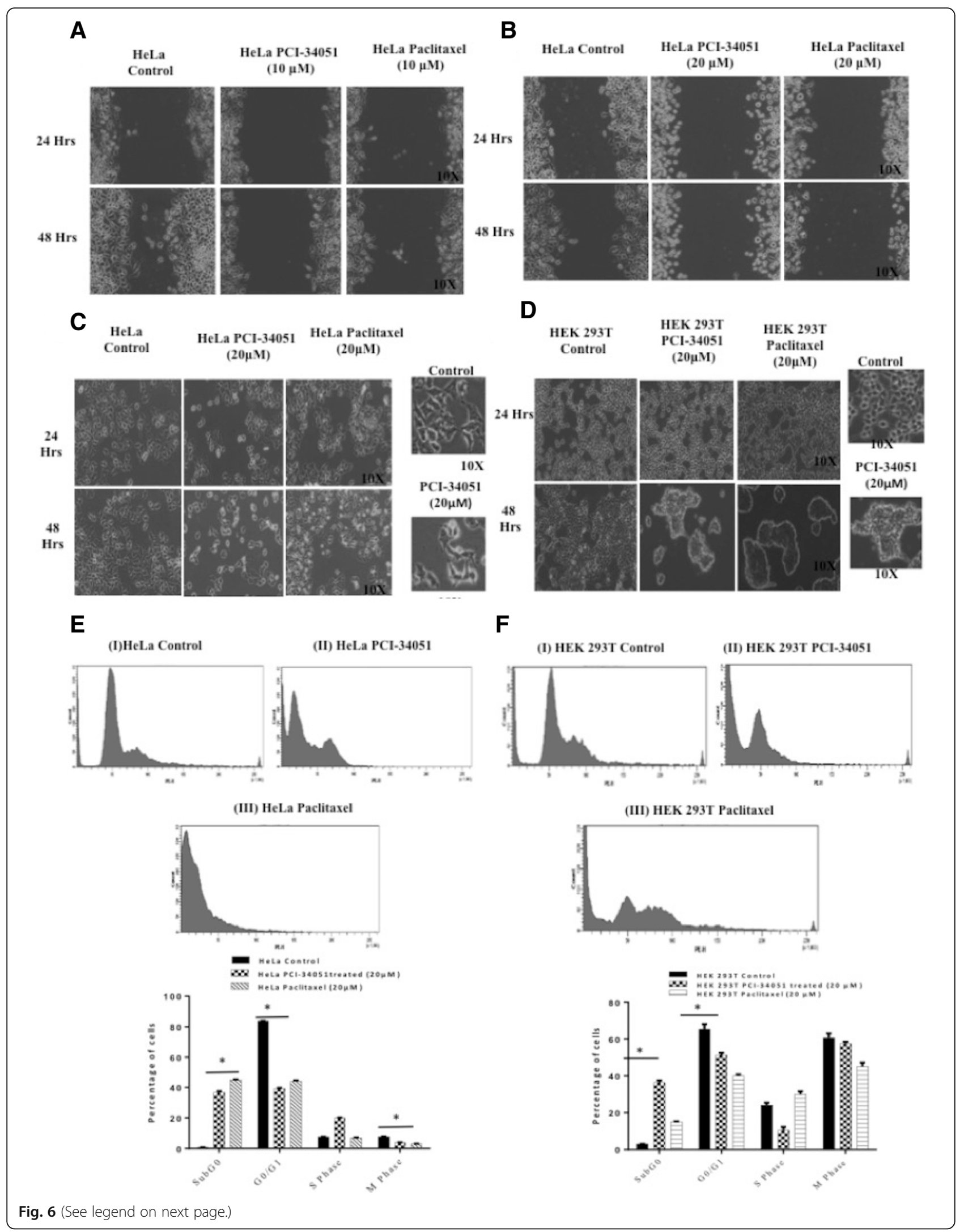


(See figure on previous page.)

Fig. 6 HDAC8 alters Alpha tubulin Functionality. a Cell Migration Assay in HeLa cells in absence or presence of PCl-34051 (10 $\mu$ M) or Paclitaxel $(10 \mu M)$ Migration efficiency: Control> > Paclitaxel>PCI-34051. b Cell Migration Assay in HeLa cells in absence or presence of PCl-34051 (20 $\mu$ M) or Paclitaxel $(20 \mu \mathrm{M})$. c Cell morphology analysis demonstrating reduced (shrinking) cell size of HeLa with PCl-34051 (20 $\mu \mathrm{M})$ or Paclitaxel (20 $\mu \mathrm{M})$ at

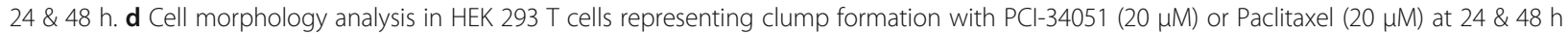
signifying role of HDAC8 in microtubule organization. e Cell cycle analysis of HeLa, showing (I) control, (II) PCl-34051 (20 $\mu$ M) and (III) Paclitaxel $(20 \mu \mathrm{M})$ treated condition. $\mathbf{f}$ Graphical representation of subG0, G0/G1, S and M phase in HeLa, deciphering significant effect of PCl-34051(20 $\mu \mathrm{M})$ on Mitotic phase. ${ }^{*}$ indicates $p$-value $<0.05$

why this functional redundancy between HDAC6 and HDAC8. So, we first analysed the expression of HDAC6 and HDAC8 in normal and cancerous cervical tissue samples in The Human Protein Atlas database and learned that HDAC6 expression is low in cervical cancer tissues when compared to normal cervix (medium expression) and that HDAC8 is overexpressed (low-medium expression) in cancerous cervix when compared to undetectable expression in normal cervix [38]. We have confirmed the expression of HDAC6 in different cancer cell lines of various origins i.e., HeLa, HCT11, A549, K562 \& MDAMB 231. There was no significant change in the expression of HDAC6 in between HEK 293 T, HeLa and HCT11 cell lines, when compared to A549, K562 \& MDA-MB 231. Whereas, HDAC8 expression was observed to be high in HeLa, A549, HCT11 \& MDA-MB 231. These immunoblot results are in agreement with human protein atlas data, suggesting differential expression pattern of HDAC6 \& HDAC8 in different cancer cell lines, assigning their specific/independent roles in deacetylating their target substrates. Further, results from our studies state dominant expression of HDAC8 in HeLa cells to that of HEK 293 T, when compared to HDAC6 expression, which did not vary significantly in both cell lines further confirming with the human protein atlas database. These results increased the probability of considering HDAC8 in taking over the function of a tubulin deacetylase in HeLa, compared to HDAC6. To further confirm this, inhibition studies were carried out. HDAC8 inhibition (PCI-34051) contrastingly increased the acetylation of alpha tubulin in HeLa, when compared to HEK 293 T. Dual inhibition of both HDAC6\&8 further increased the acetylation in a synergistic manner attributing to their independent role in deacetylating acetylated alpha tubulin. HDAC8 knockdown studies, confirms the importance of HDAC8 role as one of the tubulin deacetylase in HeLa cells.

Tubulins are one of the major cytoskeletal proteins and consists of alpha, beta and gamma tubulin proteins in the

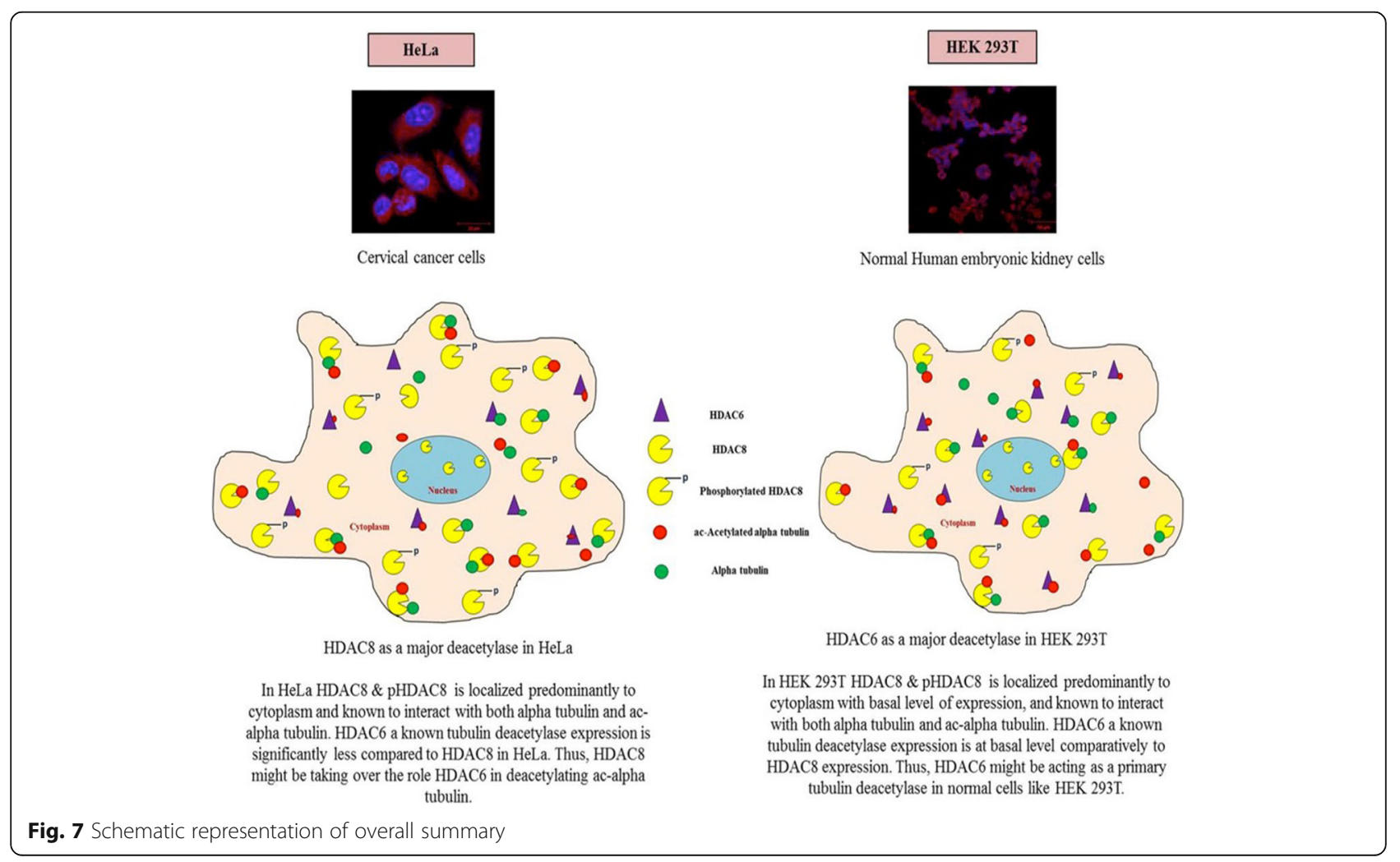


family [39]. Acetylated alpha tubulin is known to stabilize microtubules and effect intracellular transport, cell migration [40] and primary determinant for cell morphology [41]. HDAC8 inhibition impedes the migration property in HeLa in turn affecting the morphology. Shrinkage of cell size in HeLa and clump formation in HEK 293 T may be due to disruption in the cytoskeletal machinery in maintaining cell structure. The effect was quite comparable to that of paclitaxel treated condition which was considered as a positive control for tubulin inhibition. This can be explained due to the functional role of HDAC8 in deacetylating the acetylated alpha tubulin in HeLa, which is considered as a mark for stabilization of microtubules. Degree of tubulin acetylation is also known to affect the cell motility by altering the microtubule dynamics [42]. Owing to the important role of microtubules in cell cycle, inhibition of tubulin polymerization with inhibitors such as paclitaxel or inhibition of tubulin deacetylation results in cell-cycle arrest and cell death [43]. Our results demonstrate the significant $(p<0.05)$ reduction in mitotic phase in HeLa treated with PCI-34051, when compared to HEK 293 T that justifies the role of HDAC8 in HeLa as predominant deacetylase of alpha tubulin, which is in turn involved in regulating cell cycle in G2/M phase. Whereas, no major significant change in the mitotic phase of HEK $293 \mathrm{~T}$ condition can be explained due to the availability of HDAC6 that might be functioning as tubulin deacetylase even upon HDAC8 inhibition.

\section{Conclusions}

Overall, the study objective was to identify novel HDAC8 substrates and the results of our study clearly signify HDAC8 as a tubulin deacetylase. Although HDAC6 is a proven tubulin deacetylase and HDAC6 inhibition results in cancer cell death, its expression is not altered in cervical cancer as evident by the mRNA, protein expression and enzyme activity studies. Therefore, inhibition of HDAC6 in these tumours might result in undesired side effects. The study demonstrated that inhibition or knockdown of HDAC8 in HeLa cells, leads to hyper acetylation of tubulin which in turn stabilizes the microtubules and inhibit cell migration and mitotic phase of cell cycle. Our study signifies the role of HDAC8 as tubulin deacetylase in cervical cancer cells and therefore might be a better target in these cancers (Fig. 7).

\section{Acknowledgements}

We thank Ms. Monica Kannan and Ms. Nalini for the technical assistance in MALDI-TOF-TOF and confocal microscopy respectively.

\section{Funding}

The study was partly supported by Council of Scientific and Industrial Research (Grant\#:37(1497)/11/EMR-II) and Biotech Consortium India Ltd. (BCIL) (Grant\#: BT/327/NE/TBP/2012). Infrastructural support from DST-PURSE, DBT-CREBB and DST-FIST is acknowledged. Fellowship to VGR from UGC-RGNF (RGNF-2012-13SC-AND-17902) is acknowledged.

\section{Availability of data and materials}

The datasets supporting the conclusions of this article are included within the article.

\section{Authors' contributions}

VGR performed the experiments and drafted the manuscript. HGR has done the in silico studies. AMK conceptualized the study, analysed the results and reviewed the manuscript. All authors read and approved the final manuscript.

Ethics approval and consent to participate

Not applicable.

Competing interests

The authors declare that they have no competing interests.

\section{Publisher's Note}

Springer Nature remains neutral with regard to jurisdictional claims in published maps and institutional affiliations.

\section{Author details}

${ }^{1}$ Department of Animal Biology, School of Life Sciences, University of Hyderabad, Hyderabad, TS 500046, India. ${ }^{2}$ Rue du RIA, 13003 Marseille, France.

Received: 7 January 2018 Accepted: 13 April 2018

Published online: 02 May 2018

\section{References}

1. Olson DE, Udeshi ND, Wolfson NA, Pitcairn CA, Sullivan ED, Jaffe JD, Svinkina T, Natoli T, Lu X, Paulk J, et al. An unbiased approach to identify endogenous substrates of "histone" deacetylase 8. ACS Chem Biol. 2014;9(10):2210-6.

2. Gregoretti IV, Lee YM, Goodson HV. Molecular evolution of the histone deacetylase family: functional implications of phylogenetic analysis. J Mol Biol. 2004;338(1):17-31

3. Chen $\mathrm{K}$, Zhang $X$, Wu YD, Wiest O. Inhibition and mechanism of HDAC8 revisited. J Am Chem Soc. 2014;136(33):11636-43.

4. Buggy JJ, Sideris ML, Mak P, Lorimer DD, Mclntosh B, Clark JM. Cloning and characterization of a novel human histone deacetylase, HDAC8. Biochem J. 2000;350(Pt 1):199-205.

5. Somoza JR, Skene RJ, Katz BA, Mol C, Ho JD, Jennings AJ, Luong C, Arvai A, Buggy JJ, Chi E, et al. Structural snapshots of human HDAC8 provide insights into the class I histone deacetylases. Struct. 2004;12(7):1325-34.

6. Vannini A, Volpari C, Filocamo G, Casavola EC, Brunetti M, Renzoni D, Chakravarty P, Paolini C, De Francesco R, Gallinari P, et al. Crystal structure of a eukaryotic zinc-dependent histone deacetylase, human HDAC8, complexed with a hydroxamic acid inhibitor. Proc Natl Acad Sci U S A. 2004;101(42):15064-9.

7. Vannini A, Volpari C, Gallinari P, Jones P, Mattu M, Carfi A, De Francesco R, Steinkuhler C, Di Marco S. Substrate binding to histone deacetylases as shown by the crystal structure of the HDAC8-substrate complex. EMBO Rep. 2007;8(9):879-84.

8. Dowling DP, Gantt SL, Gattis SG, Fierke CA, Christianson DW. Structural studies of human histone deacetylase 8 and its site-specific variants complexed with substrate and inhibitors. Biochemistry. 2008;47(51):13554-63.

9. Wolfson NA, Pitcairn CA, Fierke CA. HDAC8 substrates: histones and beyond Biopolymers. 2013;99(2):112-26.

10. Nakagawa M, Oda Y, Eguchi T, Aishima S, Yao T, Hosoi F, Basaki Y, Ono M, Kuwano M, Tanaka M, et al. Expression profile of class I histone deacetylases in human cancer tissues. Oncol Rep. 2007;18(4):769-74.

11. Oehme I, Deubzer HE, Wegener D, Pickert D, Linke JP, Hero B, Kopp-Schneider A, Westermann F, Ulrich SM, von Deimling A, et al. Histone deacetylase 8 in neuroblastoma tumorigenesis. Clin Cancer Res. 2009;15(1):91-9.

12. Bantscheff M, Hopf C, Savitski MM, Dittmann A, Grandi P, Michon AM, Schlegl J, Abraham Y, Becher I, Bergamini G, et al. Chemoproteomics profiling of HDAC inhibitors reveals selective targeting of HDAC complexes. Nat Biotechnol. 2011;29(3):255-65.

13. Lee $H$, Rezai-Zadeh $N$, Seto E. Negative regulation of histone deacetylase 8 activity by cyclic AMP-dependent protein kinase a. Mol Cell Biol. 2004;24(2):765-73. 
14. Lam YW, Trinkle-Mulcahy L, Lamond Al. The nucleolus. J Cell Sci. 2005; 118(Pt 7):1335-7.

15. Taylor P: Immunofluorescence of cultured cells. 2015

16. Waltregny D, De Leval L, Glenisson W, Ly Tran S, North BJ, Bellahcene A, Weidle U, Verdin E, Castronovo V. Expression of histone deacetylase 8, a class I histone deacetylase, is restricted to cells showing smooth muscle differentiation in normal human tissues. Am J Pathol. 2004; 165(2):553-64.

17. Sievers F, Wilm A, Dineen D, Gibson TJ, Karplus K, Li W, Lopez R, McWilliam H, Remmert M, Soding J, et al. Fast, scalable generation of high-quality protein multiple sequence alignments using Clustal omega. Mol Syst Biol. 2011;7:539.

18. Finn RD, Bateman A, Clements J, Coggill P, Eberhardt RY, Eddy SR, Heger A, Hetherington K, Holm L, Mistry J, et al. Pfam: the protein families database. Nucleic Acids Res. 2014;42(Database issue):D222-30.

19. Yang J, Yan R, Roy A, Xu D, Poisson J, Zhang Y. The I-TASSER suite: protein structure and function prediction. Nat Methods. 2015;12(1):7-8

20. Pierce BG, Wiehe K, Hwang H, Kim BH, Vreven T, Weng Z. ZDOCK server: interactive docking prediction of protein-protein complexes and symmetric multimers. Bioinf. 2014;30(12):1771-3.

21. Allis CWD. Chromatin and chromatin remodelling enzymes, vol. 376; 2004.

22. Deardorff MA, Bando M, Nakato R, Watrin E, Itoh T, Minamino M, Saitoh K, Komata M, Katou Y, Clark D, et al. HDAC8 mutations in Cornelia de Lange syndrome affect the cohesin acetylation cycle. Nature. 2012;489(7415):313-7.

23. Donze O, Picard D. RNA interference in mammalian cells using siRNAs synthesized with T7 RNA polymerase. Nucleic Acids Res. 2002;30(10):e46

24. Van den Wyngaert I, de Vries W, Kremer A, Neefs J, Verhasselt P, Luyten WH, Kass SU. Cloning and characterization of human histone deacetylase 8 . FEBS Lett. 2000;478(1-2):77-83.

25. Hu E, Chen Z, Fredrickson T, Zhu Y, Kirkpatrick R, Zhang GF, Johanson K, Sung CM, Liu R, Winkler J. Cloning and characterization of a novel human class I histone deacetylase that functions as a transcription repressor. J Biol Chem. 2000;275(20):15254-64.

26. Li J, Chen S, Cleary RA, Wang R, Gannon OJ, Seto E, Tang DD. Histone deacetylase 8 regulates cortactin deacetylation and contraction in smooth muscle tissues. Am J Physiol Cell Physiol. 2014;307(3):C288-95.

27. Torrano V, Navascues J, Docquier F, Zhang R, Burke LJ, Chernukhin I, Farrar $D$, Leon J, Berciano MT, Renkawitz R, et al. Targeting of CTCF to the nucleolus inhibits nucleolar transcription through a poly (ADP-ribosyl)ationdependent mechanism. J Cell Sci. 2006;119(Pt 9):1746-59.

28. Balasubramanian S, Ramos J, Luo W, Sirisawad M, Verner E, Buggy JJ. A novel histone deacetylase 8 (HDAC8)-specific inhibitor PCl-34051 induces apoptosis in T-cell lymphomas. Leukemia. 2008;22(5):1026-34.

29. Free RB, Hazelwood LA, Sibley DR. Identifying novel protein-protein interactions using co-immunoprecipitation and mass spectroscopy. Curr Protoc Neurosci. 2009;5:28. Chapter 5:Unit.

30. Sadoul K, Khochbin S. The growing landscape of tubulin acetylation: lysine 40 and many more. Biochem J. 2016;473(13):1859-68.

31. Prota AE, Bargsten K, Zurwerra D, Field JJ, Diaz JF, Altmann KH, Steinmetz MO. Molecular mechanism of action of microtubule-stabilizing anticancer agents. Sci. 2013;339(6119):587-90.

32. Ramachandran GN, Ramakrishnan C, Sasisekharan V. Stereochemistry of polypeptide chain configurations. J Mol Biol. 1963;7:95-9.

33. Hubbert C, Guardiola A, Shao R, Kawaguchi Y, Ito A, Nixon A, Yoshida M, Wang XF, Yao TP. HDAC6 is a microtubule-associated deacetylase. Nature. 2002:417(6887):455-8.

34. Lee $H$, Sengupta N, Villagra A, Rezai-Zadeh N, Seto E. Histone deacetylase 8 safeguards the human ever-shorter telomeres 1B (hEST1B) protein from ubiquitin-mediated degradation. Mol Cell Biol. 2006;26(14):5259-69.

35. Ying $M$, Huang F, Ye H, Xu H, Shen L, Huan T, Huang S, Xie J, Tian S, Hu Z, et al. Study on interaction between curcumin and pepsin by spectroscopic and docking methods. Int J Biol Macromol. 2015;79:201-8.

36. Seidel C, Schnekenburger M, Mazumder A, Teiten MH, Kirsch G, Dicato M, Diederich M. 4-Hydroxybenzoic acid derivatives as HDAC6-specific inhibitors modulating microtubular structure and HSP90alpha chaperone activity against prostate cancer. Biochem Pharmacol. 2016;99:31-52.

37. Ding N, Ping L, Feng L, Zheng X, Song Y, Zhu J. Histone deacetylase 6 activity is critical for the metastasis of Burkitt's lymphoma cells. Cancer Cell Int. 2014;14(1):139.

38. Uhlen M, Bjorling E, Agaton C, Szigyarto CA, Amini B, Andersen E Andersson AC, Angelidou P, Asplund A, Asplund C, et al. A human protein atlas for normal and cancer tissues based on antibody proteomics. Mol Cell Proteomics. 2005:4(12):1920-32.

39. Williams RC Jr, Shah C, Sackett D. Separation of tubulin isoforms by isoelectric focusing in immobilized $\mathrm{pH}$ gradient gels. Anal Biochem. 1999;275(2):265-7.

40. Akhshi TK, Wernike D, Piekny A. Microtubules and actin crosstalk in cell migration and division. Cytoskeleton (Hoboken). 2014;71(1):1-23.

41. John H. Byrne RH, M. Neal Waxham: From molecules to networks: an introduction to cellular and molecular vol. III; 2014

42. Palazzo A, Ackerman B, Gundersen GG. Cell biology: tubulin acetylation and cell motility. Nature. 2003:421(6920):230.

43. Arora S, Wang XI, Keenan SM, Andaya C, Zhang Q, Peng Y, Welsh WJ. Novel microtubule polymerization inhibitor with potent antiproliferative and antitumor activity. Cancer Res. 2009;69(5):1910-5.

\section{Ready to submit your research? Choose BMC and benefit from:}

- fast, convenient online submission

- thorough peer review by experienced researchers in your field

- rapid publication on acceptance

- support for research data, including large and complex data types

- gold Open Access which fosters wider collaboration and increased citations

- maximum visibility for your research: over $100 \mathrm{M}$ website views per year

At BMC, research is always in progress.

Learn more biomedcentral.com/submissions 